\title{
The combined effects of temperature and aromatase inhibitor on metamorphosis, growth, locomotion, and sex ratio of tiger frog ( Hoplobatrachus rugulosus) tadpoles
}

\author{
Yun Tang ${ }^{1,2}$, Zhi-Qiang Chen ${ }^{1,3}$, You-Fu Lin ${ }^{1,4}$, Jing-Yi Chen ${ }^{1}$, Guo-Hua Ding ${ }^{\text {Corresp., } 1}$, Xiang Ji ${ }^{2}$ \\ ${ }^{1}$ Laboratory of Amphibian Diversity Investigation, College of Ecology, Lishui University, Lishui, Zhejiang, P. R. China \\ 2 College of Life Sciences, Nanjing Normal University, Nanjing, Jiangsu, P. R. China \\ 3 College of Animal Science and Technology, Zhejiang A \& F University, Linan, Zhejiang, P. R. China \\ 4 College of Forestry, Nanjing Forestry University, Nanjing, Jiangsu, P. R. China \\ Corresponding Author: Guo-Hua Ding \\ Email address: guwoding@qq.com
}

Background. The tiger frog (Hoplobatrachus rugulosus) is widely raised by many farms in southern region of China as an economically edible frog. The growth, development, and sexual differentiation of amphibians are influenced by temperature and steroid hormone level. However, the problem of hormone residues is caused by the addition of exogenous hormones in frog breeding, it is worth considering whether non-sterol aromatase inhibitors can be used instead of hormones.

Methods. In our study, H. rugulosus tadpoles were subjected to two water temperatures $\left(29^{\circ} \mathrm{C}\right.$ and 34 ${ }^{\circ} \mathrm{C}$ ) and three letrozole concentrations in the feed $(0,0.1$ and $1 \mathrm{mg} / \mathrm{g})$ to examine the effects of temperature, aromatase inhibitor and their interaction on metamorphosis, locomotion, and sex ratios. A G-test and contingency table were used to analyze the metamorphosis rate of tadpoles and the survival rate of froglets after feeding for 90 days. A G-test was also used to analyze sex ratio $\mathrm{s}$ in different treatment groups.

Results. Metamorphosis time and body size (snout-vent length, body mass and condition factor) were significantly different between the two temperature treatments. Metamorphosis time was longer and body size was increased at $29{ }^{\circ} \mathrm{C}$ compared to those at $34{ }^{\circ} \mathrm{C}$. Letrozole concentration and the temperature $\times$ letrozole interaction did not affect these variables. The jumping distance of froglets following metamorphosis was positively associated with the condition factor; when controlling for condition factor, jumping distance was not affected by temperature, letrozole concentration and their interaction. Temperature and letrozole concentration also did not affect metamorphosis and survival rate. Sex ratio of the control group ( $0 \mathrm{mg} / \mathrm{g}$ letrozole ) was $1: 1$ at $29^{\circ} \mathrm{C}$, but there were more males at $34^{\circ} \mathrm{C}$. The sex ratios of $\mathrm{H}$. rugulosus treated with letrozole at $29^{\circ} \mathrm{C}$ and $34^{\circ} \mathrm{C}$ were significantly biased toward males, and male ratio increased as letrozole concentration increased. Furthermore, more males were produced at $34{ }^{\circ} \mathrm{C}$ than at $29^{\circ} \mathrm{C}$ at each letrozole concentration. 


\section{The combined effects of temperature and aromatase}

2 inhibitor on metamorphosis, growth, locomotion, and

3 sex ratio of tiger frog (Hoplobatrachus rugulosus)

\section{4 tadpoles}

6 Yun Tang ${ }^{1,2}$, Zhi-Qiang Chen ${ }^{1,3}$, You-Fu Lin ${ }^{1,4}$, Jing-Yi Chen ${ }^{1}$, Guo-Hua Ding ${ }^{1, \bigotimes}$, Xiang Ji ${ }^{2}$ 7

$8{ }^{1}$ Laboratory of Amphibian Diversity Investigation, College of Ecology, Lishui University,

9 Lishui 323000, P. R. China

$10{ }^{2}$ College of Life Sciences, Nanjing Normal University, Nanjing 210046, Jiangsu, P. R. China

$11{ }^{3}$ College of Animal Science and Technology, Zhejiang A \& F University, Linan311300,

12 Zhejiang, P. R. China

${ }^{4}$ College of Forestry, Nanjing Forestry University, Nanjing 210037, Jiangsu, P. R. China

15 Corresponding author.

16 Guo-Hua Ding

17 Laboratory of Amphibian Diversity Investigation, College of Ecology, Lishui University, Lishui

18323000 , P. R. China

19 Email address: guwoding@qq.com, guwoding@1su.edu.cn. 


\section{Abstract}

22 Background. The tiger frog (Hoplobatrachus rugulosus) is widely raised by many farms in 23 southern region of China as an economically edible frog. The growth, development, and sexual 24 differentiation of amphibians are influenced by temperature and steroid hormone level. However, 25 the problem of hormone residues is caused by the addition of exogenous hormones in frog 26 breeding, it is worth considering whether non-sterol aromatase inhibitors can be used instead of 27 hormones.

28 Methods. In our study, H. rugulosus tadpoles were subjected to two water temperatures $\left(29^{\circ} \mathrm{C}\right.$ 29 and $\left.34^{\circ} \mathrm{C}\right)$ and three letrozole concentrations in the feed $(0,0.1$ and $1 \mathrm{mg} / \mathrm{g})$ to examine the 30 effects of temperature, aromatase inhibitor and their interaction on metamorphosis, locomotion, and sex ratios. A G-test and contingency table were used to analyze the metamorphosis rate of tadpoles and the survival rate of froglets after feeding for 90 days. A G-test was also used to analyze sex ratios in different treatment groups.

Results. Metamorphosis time and body size (snout-vent length, body mass and condition factor) were significantly different between the two temperature treatments. Metamorphosis time was longer and body size was increased at $29^{\circ} \mathrm{C}$ compared to those at $34{ }^{\circ} \mathrm{C}$. Letrozole concentration and the temperature $\times$ letrozole interaction did not affect these variables. The jumping distance of froglets following metamorphosis was positively associated with the condition factor; when controlling for condition factor, jumping distance was not affected by temperature, letrozole concentration and their interaction. Temperature and letrozole concentration also did not affect metamorphosis and survival rate. Sex ratio of the control group (0 mg/g letrozole) was 1:1 at 29 ${ }^{\circ} \mathrm{C}$, but there were more males at $34{ }^{\circ} \mathrm{C}$. The sex ratios of $H$. rugulosus treated with letrozole at $29^{\circ} \mathrm{C}$ and $34^{\circ} \mathrm{C}$ were significantly biased toward males, and male ratio increased as letrozole concentration increased. Furthermore, more males were produced at $34{ }^{\circ} \mathrm{C}$ than at $29{ }^{\circ} \mathrm{C}$ at each letrozole concentration.

Key words: aromatase inhibitor; Hoplobatrachus rugulosus; locomotion; metamorphosis; sex 48 ratio; tadpole; temperature 


\section{INTRODUCTION}

50 The growth and sex differentiation of amphibians are often influenced by the environment,

51 and the effect of temperature has received much attention from researchers. Previous studies

52 have found that the hatching success rate and survival rate of amphibians are significantly

53 affected by temperature (Wang \& Li, 2007; Fu \& Xu, 2014). During the development of

54 tadpoles, high temperature accelerates the growth rate and reduces the duration of

55

metamorphosis and time to sexual maturation (Wang \& Li, 2007; Liu et al., 2006; Wang et al.,

56 2005). However, high temperatures can lead to malformations or even death, while low

57 temperatures can lead to the failure of metamorphosis (Wang \& Li, 2007; Wang et al., 2005).

58 The growth and development of amphibians is also reflected by locomotion, previous studies

59 have focused on the relationship between temperature and locomotion (Huey and Stevenson,

60 1979; Tracy, 1979; Rome et al., 1992). In addition, gonadal differentiation in amphibians is not

61 completely controlled by genes, and environmental factors such as temperature affect gonadal

62 differentiation to determine phenotypic sex (Tompsett et al., 2013). Previous studies reported that

63 tadpoles experiencing extreme temperatures exhibited a significant shift in phenotypic sex ratio

64 of the offspring (Nakamura, 2009). Tadpoles from families such as Bufonidae, Ranidae, and

65 Dicroglossidae are biased toward developing as males at high temperatures and females at low

66 temperatures (Li et al., 2001; Li et al., 2007; Dournon et al., 1990; Piquet, 1930; Yoshikura,

67 1959; Hsü et al., 1971; Fu, 2010). However, the sensitivity of sex ratio variation to temperature

68 is not consistent in different species. Moreover, gonadal differentiation is more significantly

69 affected by temperature when tadpoles develop to a certain period, and the period is called

70 thermosensitive period (Kraak \& Pen, 2002).

71 In addition to temperature, previous studies have shown that steroid hormones can affect the

72 metamorphosis of amphibians (Hayes et al., 1993; Hayes, 1997). However, few studies have

73 assessed the effect of steroid hormones on amphibian growth, development, and locomotion with

74 most studies focusing on effects on gonad development and phenotypic sex ( $L i$ \& Lin, 2000;

75 Nakamura, 2009; 2010; 2013). Generally, exogenous testosterone or dihydrotestosterone lead to 
76 masculinization of females (Nishioka et al., 1993; Martyniuk et al., 2013), while exogenous

77 estradiol can feminize males into females (Zhang \& Witschi, 1956), and even offset the

78 temperature-induced sex reversal effect. For example, adding estradiol to water at high

79 temperature does not skew the sex ratio in amphibian populations (Nakamura, 2009). However,

80 the effects are not consistent on different species and may even be variable within a species in a

81 dose-dependent manner (Nakamura, 2009; Piprek et al., 2012; Stephanie et al., 2016).

82 Researchers have found that during steroid hormone synthesis in vertebrates, Cytochrome P450

83 17 $\alpha$-hydroxylase and 17,20 lyase (CYP17) can promote the conversion of progesterone to

84 dehydroepiandrosterone in amphibians (Maruo et al., 2008), unregulated gene expression in

85 indifferent gonads of males, and then maintain this at a high level (Iwade et al., 2008);

86 cytochrome P450 aromatase (CYP19) can transform testosterone into estradiol (Maruo et al.,

87 2008) and is expressed at a higher level in the undifferentiated gonads of females (Kuntz et al.,

88 2003a,b; Kato et al., 2004). For example, in female tadpoles injected with testosterone, the

89 activity of CYP17 is enhanced and that of CYP19 is inhibited to a certain extent under conditions

90 of high estradiol concentration (Yoshikura, 1959).

91 Most previous studies have used exogenous testosterone and estradiol to explore their

92 influence on sex differentiation (Hayes et al., 1993; Hayes, 1997; Oike et al., 2016). In fact, the

93 levels of testosterone and estradiol can be directly regulated by altering the activity of aromatase

94 in the steroid hormone synthesis pathway in animals (Foidart et al., 1994; Nathan et al., 2001;

95 Urbatzka et al., 2007). The aromatase inhibitor can inhibit the activity of aromatase (Li et al.,

96 2007), block the transformation of testosterone to estradiol, and reverse the transition from

97 female to male or masculinize the gonads (Yu et al., 1993; Chardard \& Dournon, 1999; Miyata

$98 \&$ Kubo, 2000). Previously, the effects of aromatase inhibitors on steroid hormone levels and

99 gonadal development has been increasingly reported in Ribbed Newt Pleurodeles waltl

100 (Chardard \& Dournon, 1999) and American Bullfrog Rana catesbeiana (Yu et al., 1993). Studies

101 have shown that several aromatase inhibitors (e.g., fadrozole and 4-hydroxyandrostenedion) can

102 induce the masculinization of amphibian ovaries (Chardard \& Dournon, 1999; Duarte- 
103 Guterman et al., 2009; Miyata \& Kubo, 2000; Olmstead et al., 2008; Yu et al., 1993), resulting

104 in intersexed gonads or even complete masculinization (Chardard \& Dournon, 1999; Olmstead

105 et al., 2008). In contrast, other aromatase inhibitors (e.g., aminoglutethimide) have no effect on

106 amphibian gonads (Chardard \& Dournon, 1999), while miconazole has been found to have a

107 toxic effect on amphibian tadpoles (Chardard \& Dournon, 1999). In addition, a close correlation

108 between testosterone levels and muscle strength was reported in humans (Nam et al., 2018),

109 which suggests that testosterone might affect the locomotion of animals by improving muscle

110 strength. Aromatase inhibitors can regulate testosterone levels in organisms, but whether

111 aromatase inhibitors can affect the locomotion of animals needs to be tested.

112 As stated, numerous studies have reported that temperature, steroid hormones, and

113 aromatase inhibitors play important roles in amphibian growth or sex development (Hayes et al.,

114 1993; Hayes, 1997; Chardard \& Dournon, 1999), but these factors might interact during

115 amphibian life, and such interactions still need to be studied. Early studies have reported

116 interactions between temperature and steroids, with resulting effects on amphibian larval growth,

117 development, and metamorphosis (Hayes et al., 1993); however, the effects of these interactions

118 on amphibian sex development have rarely been assessed. Aromatase inhibitors do not exist in

119 nature, but they have become more widely used in recent years because they can affect the levels

120 of endogenous steroid hormones and are associated with better hormonal regulation than

121 exogenous steroid hormones (Miyata \& Kubo, 2000; Olmstead et al., 2009; Shen et al., 2013; Singh

122 et al., 2015). Given the state of research on aromatase inhibitors and the potential effects of

123 steroids on anuran larval growth and development, an investigation of the interactive effects of

124 temperature and aromatase inhibitors on growth and sex development is warranted. Fadrozole is

125 an aromatase commonly used for amphibians (Olmstead et al., 2009), but in other animals like

126 fish and reptiles (Noëlle et al., 1995; Shen et al., 2013; Singh et al., 2015), the aromatase

127 inhibitor letrozole (Lamb \& Adkins, 1998) prevents the conversion of testosterone to estradiol,

128 thereby altering the levels of steroid hormones in organisms. Letrozole has shown high

129 selectivity for and the potential to inhibit aromatase (Shen et al., 2013). Moreover, it was found 
130 to exert a stronger effect than fadrozole in the European Pond Turtle Emys orbicularis (Noëlle et 131 al., 1995), but it has rarely been used as an aromatase inhibitor in amphibians.

132 Hoplobatrachus rugulosus, a large robust dicroglossid frog, is listed in Appendix II of

133 CITES as a national Class II protected species in China (Fei et al., 2012). It is widespread form

134 the southern region of the Yangtze River within China to Myanmar, Laos, Vietnam, Cambodia

135 and Thailand, and inhabits a variety of lowland habitats including intermittent freshwater

136 marshes and seasonally flooded agricultural land (Fei et al., 2012). Hoplobatrachus rugulosus is

137 considered an economically edible frog species in China, owing to its delicious and nutritious

138 meat (Ding et al., 2015). In China, there are many frog farms that raise H. rugulosus since 1980s

139 (Zhan \& Yang, 2012). These farms should consider the production efficiency and economic

140 efficiency with different sexes of frogs, and it is known that sex ratio bias induced by

141 temperature has a high practical value, but the economic efficiency is not as good as that induced

142 by hormones $(F u, 2010)$. However, hormone residues are harmful, and it is worth considering

143 whether non-sterol aromatase inhibitors can be used instead of hormones. In our study, the

144 effects of different temperatures and letrozole concentrations on the metamorphosis, growth,

145 locomotion, and sex of H. rugulosus tadpoles were studied. Furthermore, the combined effects of 146 environmental temperature and aromatase inhibitors on the phenotypic traits of $H$. rugulosus

147 tadpoles were also evaluated. The purpose of our study was to elucidate the internal and external

148 factors influencing the growth, development, and sexual differentiation of $H$. rugulosus, and to

149 provide a basic reference for the artificial breeding of this species.

\section{MATERIALS AND METHODS}

151

152

153

154

155

156

\section{Animal collection and treatment}

Our experimental procedures were specifically approved by the Animal Research Ethics Committee of College of Ecology in Lishui University (Permit No. AREC-CELSU 201505-001).

In June 2015, four clutches of fertilized eggs of H. rugulosus were collected from the amphibian laboratory of Lishui University. They were placed in plastic bins (length $\times$ width $\times$ height $=50 \mathrm{~cm} \times 40 \mathrm{~cm} \times 35 \mathrm{~cm}$ ) with $30 \mathrm{~L}$ water, and the boxes were moved to an outdoor 
157 shelter. Through natural incubation, the fertilized eggs developed into tadpoles at Gosner 25.

158 Then, 135 tadpoles from each clutch were randomly selected and mixed. All 540 tadpoles were

159 divided into six groups and placed into six food-grade polypropylene plastic bins with $50 \mathrm{~L}$ of

160 aerated water. The population density of $H$. rugulosus tadpoles will significantly affect their

161 metamorphosis (Ding et al., 2015); therefore, the initial density was maintained at 1.8

162 individuals/L.

163 Previous studies on the effects of aromatase inhibitors in amphibian species were conducted

164 by mixing the aromatase inhibitors into feed (Chardard \& Dournon, 1999), putting the

165 aromatase inhibitors in the water (Duarte-Guterman et al., 2009), or implanting the capsules

166 with aromatase inhibitors on the mesenteries of tadpoles (Yu et al., 1993). Letrozole is insoluble in

167 water, and it is difficult to implant the capsules on the mesenteries of tadpoles. Therefore, in our

168 study, we decided to mix the letrozole into the feed. Before the experiment, $0.02 \mathrm{~g}$ and $0.2 \mathrm{~g}$

169 letrozole was dissolved in $100 \mathrm{~mL}$ of anhydrous ethanol, and the two treatment solutions were

170 evenly sprayed and stirred into $200 \mathrm{~g}$ frog feed (Ningbo Tech-Bank Co., Ltd., Ningbo, China;

171 water $\leq 12.0$, crude protein $\geq 42.0$, crude fat $\geq 3.0$, crude fiber $\leq 4.0$, crude ash $\leq 18.0$, calcium $\geq 1.5$,

172 total phosphorus $\geq 1.0$, and salt $\leq 3.0$ ). The feed for the control group was only sprayed with 100

$173 \mathrm{~mL}$ anhydrous ethanol. The three kinds of feeds were then oven heated at $50{ }^{\circ} \mathrm{C}$ for $2 \mathrm{~h}$ to

174 completely volatilize the ethanol, and the feeds with letrozole concentration of $0 \mathrm{mg} / \mathrm{g}, 0.1 \mathrm{mg} / \mathrm{g}$,

175 and $1 \mathrm{mg} / \mathrm{g}$ were prepared for later use. In previous studies, researchers have found that the body

176 temperature preference for the growth and development of H. rugulosus tadpoles is $28.2^{\circ} \mathrm{C}($ Fan

177 et al., 2012). Another study found that the sex ratio was biased toward males at $30^{\circ} \mathrm{C}$ and that

$178100 \%$ masculinization occurred at $35^{\circ} \mathrm{C}(\mathrm{Fu}, 2010)$, suggesting that high temperatures can make

179 H. rugulosus tadpoles produce more male offspring. Therefore, we used 29 and $34{ }^{\circ} \mathrm{C}$ for tadpole

180 feeding experiments based on these previous studies. There were two (water temperature: $29{ }^{\circ} \mathrm{C}$

181 and $34^{\circ} \mathrm{C}$ ) $\times$ three (letrozole concentration in feed: $0 \mathrm{mg} / \mathrm{g}, 0.1 \mathrm{mg} / \mathrm{g}$, and $1 \mathrm{mg} / \mathrm{g}$ ) experimental

182 treatments designed. Six bins were used, and the water temperature inside the bins was

183 controlled by two $300 \mathrm{~W}$ heating rods. Three bins of tadpoles at each temperature were fed with 
184 different letrozole concentration feeds at 8:00 daily. During the first week of the experiment, 0.3

$185 \mathrm{~g}$ feed was added to each bin daily. After the first week, 10 tadpoles were randomly selected

186 from each bin and removed with a net every 2 days. These were weighed after towel drying, and

$18710 \%$ of the mean weight of the tadpole was used as the feed mass for the next 3 days. The water

188 and excreta at the bottom of the bins was pumped out every 2 days and replaced with the same

189 amount of fresh aerated water. The water volume was determined by the number of surviving

190 tadpoles, so that the tadpole density was maintained at 1.8 individuals/L. The amount of water

191 changed each time was about half of the whole bin.

192 Data measurement

193 After complete metamorphosis of tadpoles (Gosner 46) (Gosner, 1960), metamorphosis time

194 of each individual and metamorphosis number were recorded, and the snout-vent length (SVL,

195 the distance from the snout to the cloaca orifice) and body mass of the first 20 froglets to

196 complete metamorphosis in each treatment group were measured with a digital caliper and

197 electronic scale. Only comparing the SVL or weight was not enough to reflect the overall body

198 size of $H$. rugulosus and the condition factor was defined as the body mass divided by the SVL

199 (Hu et al., 2019). Therefore, we used the condition factor as the overall indicator of body size.

200 Then, the froglets were put into a lidded plastic bowl (diameter, $10 \mathrm{~cm}$ ) with a saturated sponge

201 and stood for $1 \mathrm{~h}$ at $25-28^{\circ} \mathrm{C}$. After that, the feet of the froglets were colored with green pigment

202 and placed on flat ground without obstacles. Then, the froglets were touched on the tail bone

203 with a glass rod to initiate jumping onto a white gauze three times in a row (jumping from where

204 they landed from the previous jump), and the distance was measured with a digital caliper ( \pm

$2050.01 \mathrm{~mm}$ ). The average distance was taken as the jumping ability. PIT animal tags (HT100, 0.02g,

206 length $\times$ diameter $=7.5 \mathrm{~mm} \times 1.2 \mathrm{~mm}$, Guangzhou Hongteng Barcode Technology Co. Ltd.

207 Guangzhou, China) were subcutaneously injected to mark individual froglets. After injection, a

208 sponge saturated with water was placed in the cage, and the froglet was placed in the cage to

209 recover. The froglets were returned to the pool to continue feeding after the wound healed. The

210 froglets were reared in separate outdoor breeding ponds (length $\times$ width $\times$ height $=3 \mathrm{~m} \times 1.8 \mathrm{~m}$ 
$211 \times 1 \mathrm{~m}$ ) according to the different treatments, and the outdoor environment was simulated in the 212 ponds (5 $\mathrm{cm}$ silt on the bottom; $10 \mathrm{~cm}$ water depth). Myriophyllum verticillatum and Hydrocotyle 213 vulgaris were planted in the ponds, and Azolla imbricata floated on the water surface. To 214 determine the feed mass, $10 \%$ of the mean weight of the froglets $\times$ the froglet number was 215 calculated every 3 days, and remaining feed was removed after 3 hours. The number of surviving 216 individuals was recorded after 90 days of feeding and used to calculate the survival rate for the 217 froglets. Some individuals died after metamorphosis, and we randomly selected some of them for 218 gonadal dissection (5-10 dead froglets in each treatment) to estimate the number of male and 219 female individuals in each treatment surviving after 90 days. Males were considered to be those 220 with a pair of vocal sacs, and the others were considered females. If the body length of an 221 individual without vocal sacs was $<55 \mathrm{~cm}$, then the sex was determined by anatomical 222 observation of the gonads after euthanasia with MS-222 (400 ppm). The male ratio of each 223 treatment group was calculated by combining the estimated number of male and female 224 individuals who died and the number of male and female individuals who survived after 90 days.

\section{Statistical analysis}

Before further statistical analysis, normality and homogeneity of all data were verified by the Kolmogorov-Smirnov test and the Bartlett's test, respectively. A log likelihood-ratio test (Gtest) and contingency table were used to evaluate the metamorphosis rate and survival rate of froglets after feeding for 90 days. The G-test was used to analyze the sex ratios of $H$. rugulosus in different treatment groups. Linear regression analysis was used to analyze the relationship between jumping distance and condition factor. With temperature and aromatase inhibitor concentration as factors, two-way ANOVA was used to analyze the differences in metamorphosis time, individual size, and residual value of jumping distance against condition 234 factor among different treatments. Tukey multiple comparisons were used to analyze the differences. All statistical tests were performed using the STATISTICA software package (version 6.0). All results are presented as mean $\pm \mathrm{SE}$, and the differences were considered statistically significant at $P<0.05$. 
238 RESULTS

239 The metamorphosis rate of $H$. rugulosus tadpoles under different treatments ranged from

$24055.6-73.3 \%(61.5 \pm 3.0 \%$ average $)$. The set temperature and letrozole concentration did not

241 affect the metamorphosis rate of tadpoles $(\mathrm{G}=10.74, \mathrm{df}=5, P>0.05$; Fig. 1). The

242 metamorphosis time, SVL, body mass, and condition factor after complete metamorphosis were

243 significantly different between the two temperatures. Treatment at $29^{\circ} \mathrm{C}$ prolonged the

244 metamorphosis time and increased the SVL, body mass, and condition factor of the froglets

245 compared with those at $34{ }^{\circ} \mathrm{C}$. However, different letrozole concentration and the interaction

246 between temperature and letrozole concentration did not affect the four indicators (Table 1). The

247 jumping distance of froglets was positively correlated with condition factor $\left(\mathrm{F}_{1,118}=13.88, \mathrm{P}<\right.$

2480.001 ; Fig. 2A). After controlling for the effect of the condition factor, jumping distance was not

249 affected by temperature $\left(\mathrm{F}_{1,114}=0.92, P=0.339\right)$, letrozole concentration $\left(\mathrm{F}_{2,114}=2.04, P=\right.$

250 0.134), or their interaction $\left(\mathrm{F}_{2,114}=2.96, P=0.056\right)$ (Fig. 2B).

251 There was no significant difference in the froglets survival rate of $H$. rugulosus in the six 252 treatment groups after 90 days of feeding $(\mathrm{G}=2.83, \mathrm{df}=5, \mathrm{P}=0.727)$, with an average survival 253 rate of $49.7 \pm 2.1 \%(42 \%-56.1 \%$, Fig. 3A). Under the non-letrozole treatment, the sex ratio of 254 H. rugulosus froglets was maintained at $1: 1$ at $29{ }^{\circ} \mathrm{C}(54.9 \%$ male, $45.1 \%$ female; $\mathrm{G}=0.49$, $\mathrm{df}$ $255=1, P=0.483)$. However, the proportion of males was higher at $34{ }^{\circ} \mathrm{C}(86 \% ; \mathrm{G}=28.82, \mathrm{df}=1$, $256 P<0.001)\left(\right.$ Fig. 3B). Exposed to letrozole, the sex ratio of froglets at both $29{ }^{\circ} \mathrm{C}$ and $34{ }^{\circ} \mathrm{C}$ was 257 significantly biased toward males $\left(0.1 \mathrm{mg} / \mathrm{g}\right.$ at $29{ }^{\circ} \mathrm{C}: 83.6 \%, 0.1 \mathrm{mg} / \mathrm{g}$ at $34{ }^{\circ} \mathrm{C}: 98.1 \%, 1 \mathrm{mg} / \mathrm{g}$ 258 at $29^{\circ} \mathrm{C}: 92.4 \%, 1 \mathrm{mg} / \mathrm{g}$ at $34{ }^{\circ} \mathrm{C}: 100 \%$; all $P<0.001$ ) (Fig. 3B). The male ratio increased 259 with letrozole concentration (both $P<0.01$ ) at both temperatures, while more males were 260 produced at $34{ }^{\circ} \mathrm{C}$ than at $29^{\circ} \mathrm{C}$ at each letrozole concentration (both $P<0.05$ ) (Fig. 3B).

\section{DISCUSSION}

262 The influence of temperature on the life history of ectotherms has been previously studied 263 by several researchers (e.g.,Roff, 1990; Stearns, 1992; Charnov, 2004; Nie et al., 2007), and it 264 has been reported on poikilothermic species such as Eurasian Perch Perca fluviatilis (Sandstrom, 
265 1995), Japanese Medaka Oryzias latipes (Hemmer-Brepson et al., 2004) and Multiocellated 266 Racerunner Eremias multiocellata (Li et al., 2011). Metamorphosis is an important

267 developmental stage in amphibians (Meng, 2019). Here, we focused on the effects of temperature, 268 aromatase inhibitor and their interaction on the metamorphosis of $H$. rugulosus.

269 Our results showed that the metamorphosis time of H. rugulosus tadpoles at high 270 temperature was shorter than that at low temperature, but the body size of froglets decreased.

271 These results are similar to those from previous studies (Álvarez et al. 2002; Liu et al, 2006;

272 Gomez-Mestre and Buchholz, 2006), suggesting that temperature is closely related to the growth 273 of amphibians; specifically, higher temperatures might increase the metabolic activity of tadpoles 274 and accelerate their development. However, growth is affected owing to the shorter development 275 time (Wang \& Li, 2007; Wang \& Wang, 2008), and this shorter time leads to less energy being 276 accumulated and, consequently, smaller froglets. In addition to temperature, our results also 277 showed that treatment with letrozole at different concentrations had no significant effect on 278 metamorphosis time or body size of H. rugulosus froglets, which suggests that letrozole 279 concentration does not significantly affect their growth or development. Furthermore, the results 280 showed that the metamorphosis rate of tadpoles and the survival rate of froglets were not 281 significantly affected by different temperatures or letrozole concentrations. However, previous 282 studies reported that the metamorphosis rate of Chinese Brown Frog Rana chensinensis and 283 Asiatic Toad Bufo gargarizans increased with increasing temperature (Wang et al., 2005), which 284 is inconsistent with our results, suggesting that temperature is independent of the metamorphosis 285 rate of $H$. rugulosus. A possible reason for this discrepancy is that the temperature range used in 286 the present study might not have been broad enough to detect an effect as it was only $5{ }^{\circ} \mathrm{C}$ $287\left(29^{\circ} \mathrm{C}-34^{\circ} \mathrm{C}\right)$, whereas that in $\operatorname{Wang}$ et al. $(2005)$ was $20^{\circ} \mathrm{C}\left(5,15\right.$, and $\left.25^{\circ} \mathrm{C}\right)$, Thus, more data 288 is needed to determine whether temperature is related to the metamorphosis rate of amphibians. 289 Previous studies on the effects of aromatase inhibitors on amphibians mainly focused on their 290 sexual development. Further experiments on other aromatase inhibitors are needed to explore the 291 effects of aromatase inhibitors on the metamorphosis development of amphibians. Although no 
292 replicate groups were included in our study, each treatment group included a mixture of tadpoles 293 randomly selected from four different sources, thus increasing the validity and reliability of our 294 results.

295 After controlling for the effect of the condition factor, temperature did not affect the 296 jumping ability of $H$. rugulosus. Previous studies on Green Frog Rana clamitans and Northern 297 Leopard Frog Rana pipiens reported that their jump performance was relatively independent of 298 temperature within a certain range (Huey and Stevenson, 1979; Tracy, 1979) suggesting that 299 temperature within a specific range does not significantly affect the locomotion of H. rugulosus. 300 In other amphibians (e.g., African Clawed Frog Xenopus laevis, Mudpuppy Necturus maculosus, 301 R. pipiens, Spotted Grass Frog Limnodynastes tasmaniensis and Striped Marsh Frog L. peronii), 302 the locomotion performance declined rapidly at a very low or high temperature (Putnam \& 303 Bennett, 1981; Miller, 1982; Hirano \& Rome, 1984; Whitehead et al., 1989; Wilson, 2001; 304 Gomes et al.,2002). However, in our study, the temperature was maintained constant, with no 305 significant fluctuation, and the results indicated that the jumping ability of H. rugulosus is 306 independent of temperature within the range set by us. Further studies are needed to explore the 307 effect of different temperature treatments on amphibian locomotion ability. Similarly, letrozole 308 concentration did not affect the jumping ability of $H$. rugulosus, but this evidence is not 309 sufficient to conclude that aromatase inhibitors do not affect amphibian locomotion as there is 310 research on other aromatase inhibitors. Therefore, further investigations are required to ascertain 311 whether aromatase inhibitors influence amphibian locomotion.

312 The results regarding the sex ratio of H. rugulosus froglets suggested that the proportion of 313 males reaches $>80 \%$ at $34{ }^{\circ} \mathrm{C}$. However, sex ratio was not evidently biased at $29{ }^{\circ} \mathrm{C}$ in the 314 control group, which suggested that the gonads of H. rugulosus tadpoles are biased toward males 315 at high temperature. These results are similar to those reported by $F u(2010)$, and this 316 phenomenon was observed in R. chensinensis (Li et al., 2001), Hong Kong Rice-paddy Frog 317 Fejervarya multistriata (Li et al., 2007), and Giant Spiny Frog Quasipaa spinosa (Mei et al., 2018), 318 suggesting that high temperature can cause male bias in most amphibians. The results of the 
319 present study also indicated that the sex ratio is biased toward males after letrozole treatment, 320 and these results are similar to those based on Indian Skipper Frog Euphlyctis cyanophlyctis with 321 the aromatase inhibitor formestane (Phuge, 2018). In a previous study, researchers implanted 322 capsules in individuals to investigate the effects of aromatase inhibitors on sex hormones, and 323 they also found that aromatase inhibitors at a certain concentration could inhibit the activity of 324 ovarian aromatase, leading to the accumulation of testosterone and inducing the transformation 325 of ovaries to testes ( $Y$ u et al., 1993). These results indicate that aromatase inhibitors can lead to 326 the male bias. Previously, steroid hormones such as testosterone and estradiol were confirmed to 327 change the sex ratio of amphibian offspring (Nakamura, 2009; 2010; 2013), but these trials used 328 exogenous steroid hormones. In contrast, aromatase inhibitors can inhibit the transformation of testosterone to estradiol thus increasing endogenous testosterone levels, which could better reflect the regulatory mechanism of steroid hormones in vivo. In the present study, the proportion of males increased with increasing letrozole concentrations. In addition, at $29{ }^{\circ} \mathrm{C}$, the proportion of males in the control group was $28.7 \%$ higher than that in the $0.1 \mathrm{mg} / \mathrm{g}$ letrozole treatment group. However, at $34^{\circ} \mathrm{C}$, the proportion of males in the control group was $12.1 \%$

334 higher than that in the $0.1 \mathrm{mg} / \mathrm{g}$ letrozole treatment group. Therefore, we speculate that

temperature and letrozole interact to influence the sex ratio and that the effects of letrozole on the sex ratio are more obvious at lower temperatures.

\section{CONCLUSIONS}

Our results showed that (1) high temperature can accelerate the growth and development of H. rugulosus tadpoles, shorten the metamorphosis time and increase the proportion of males; (2) although the tadpoles at low temperature grew slowly, the froglets after metamorphosis were larger; (3) letrozole can induce a male bias in the tadpoles of H. rugulosus, and this male biased effect is more obvious at low temperature. While our results demonstrate the effects of temperature, letrozole concentration and their interaction on the growth, development and sex differentiation of tadpoles, the molecular mechanism should be further explored in future research. 


\section{ACKNOWLEDGEMENTS}

348 We would like to thank Ying-Ying Wang, Jing-Hao Zhu for their help during the research, and 349 would like to thank Editage (www.editage.cn) for English language editing.

350 ADDITIONAL INFORMATION AND DECLARATIONS

\section{Funding}

352 The Zhejiang Provincial Natural Science Foundation of China (LQ16C040001), National

353 Science Foundation of China (31500308) and Zhejiang Science and Technology Innovation 354 Program for College Students (2019R434006) funded this work. The funders had no role in 355 study design, data collection and analysis, decision to publish, or preparation of the manuscript.

\section{Grant Disclosures}

357 The following grant information was disclosed by the authors:

358 Zhejiang Provincial Natural Science Foundation of China: LQ16C040001

359 National Science Foundation of China: 31500308

360 Zhejiang Science and Technology Innovation Program for College Students: 2019R434006

\section{Competing interests}

362 The authors declare there are no competing interests.

\section{Authors' contributions}

364 - Yun Tang conceived and designed the experiments, performed the experiments, analyzed the 365 data, prepared figures and/or tables, authored or reviewed drafts of the paper, approved the final 366 draft.

367 - Zhi-Qiang Chen conceived and designed the experiments, performed the experiments, analyzed 368 the data, authored or reviewed drafts of the paper, approved the final draft.

369 - You-Fu Lin performed the experiments, analyzed the data, prepared figures and/or tables, 370 authored or reviewed drafts of the paper. 
371 - Jing-Yi Chen performed the experiments, contributed reagents/materials/analysis tools,

372 authored or reviewed drafts of the paper.

373 - Guo-Hua Ding conceived and designed the experiments, analyzed the data, contributed

374 reagents/materials/analysis tools, prepared figures and/or tables, authored or reviewed drafts of

375 the paper, approved the final draft.

376 - Xiang Ji conceived and designed the experiments, authored or reviewed drafts of the paper.

377 Data Availability

378 The following information was supplied regarding data availability:

379 The raw data has been supplied as Supplementary Files.

380 Supplemental Information

381 Supplemental information for this article can be found online at.

382 REFERENCES

383 Álvarez D, Nicieza AG. 2002. Effects of temperature and food quality on anuran larval growth 384 and metamorphosis. Functional Ecology 16: 640-648 DOI 10.1046/J.1365-2435.2002.00658.X.

385 Chardard D, Dournon C. 1999. Sex reversal by aromatase inhibitor treatment in the newt

386 Pleurodeles waltl. Journal of Experimental Zoology 283: 43-50 DOI 10.1002/(SICI)1097$387 \quad 010 X(19990101) 283: 1<43:: A I D-J E Z 6>3.0 . C O ; 2-G$.

388 Charnov EL. 2004. Size and Temperature in the Evolution of Fish Life Histories. Integrative 389

390

391

392

393

394 and Comparative Biology 44: 494-497 DOI 10.1093/icb/44.6.494.

Ding GH, Lin ZH, Fan XL, Ji X. 2015. The combined effects of food supply and larval density on survival, growth and metamorphosis of Chinese tiger frog (Hoplobatrachus rugulosa) tadpoles. Aquaculture 435: 398-402 DOI 10.1016/j.aquaculture.2014.10.025.

Dournon C, Houillon C, Pieau C. 1990. Temperature sex-reversal in amphibians and reptiles. International Journal of Developmental Biology 34: 81-92.

Duarte-Guterman P, Langlois VS, Hodgkinson K, Pauli BD, Cooke GM, Wade MG,

Trudeau VL. 2009. The aromatase Inhibitor fadrozole and the 5-reductase inhibitor 
397

398

399

400

401

402

403

404

405

406

407

408

409

410

411

412

413

414

415

416

417

418

419

420

421

422

finasteride affect gonadal differentiation and gene expression in the frog Silurana tropicalis. Sexual Development 3: 333-341 DOI 10.1159/000280586.

Fan XL, Lei HZ, Lin ZH. 2012. Ontogenetic shifts in selected body temperature and thermal tolerance of the tiger frog, Hoplobatrachus chinensis. Acta Ecologica Sinica 32: 55745580.

Fei L, Ye CY, Jiang JP. 2012. Colored atlas of Chinese amphibians and their distributions. Chengdu: Sichuan Science and Technology Publishing House, pp 572-573.

Foidart A, de Clerck A, Harada N, Balthazart J. 1994. Aromatase-immunoreactive cells in the quail brain: Effects of testosterone and sex dimorphism. Physiology \& Behavior 55: 453-464 DOI: 10.1016/0031-9384(94)90100-7.

Fu SH. 2010. Endangered status and protection measures of tiger frog(Hoplobatrachus rugulosus) in Hainan. Nanjing, China: Nanjing Agricultural University.

Fu SH, Xu SC. 2014. Effects of water temperature on hatching fertilized egg of tiger frog. Hubei Agricultural Sciences 53: 4924-4925.

Gomes FR, Bevier CR, Navas CA. 2002. Environmental and physiological factors influence antipredator behavior in Scinax hiemalis (Anura: Hylidae). Copeia 2002: 994-1005 DOI 10.1643/0045-8511(2002)002[0994:eapfia]2.0.co;2.

Gomez-Mestre I, Buchholz DR. 2006. Developmental plasticity mirrors differences among taxa in spadefoot toads linking plasticity and diversity. Proceedings of the National Academy of Sciences of the United States of America 103: 19021-19026 DOI

$10.1073 /$ pnas.0603562103.

Gosner KL. 1960. A simplified table for staging anuran embryos and larvae with notes on identification. Herpetologica 16: 183-190.

Hayes T, Chan R, Licht P. 1993. Interactions of temperature and steroids on larval growth, development, and metamorphosis in a toad (Bufo boreas). Journal of Experimental Zoology 266: 206-215 DOI: 10.1002/jez.1402660306. 
423 Hayes, TB. 1997. Steroids as potential modulators of thyroid hormone activity in anuran

424

425

426

427

428

429

430

431

432

433

434

435

436

437

438

439

440

441

442

443

444

445

446

447

metamorphosis. Integrative and Comparative Biology 37:185-194 DOI: 10.1093/icb/37.2.185.

Hemmer-Brepson C, Replumaz L, Romestaing C, Voituron Y, Daufresne M. 2004. Nonstressful temperature effect on oxidative balance and life history traits in adult fish (Oryzias latipes). Journal of Experimental Biology 217: 274-282. DOI 10.1242/jeb.096172.

Hirano M, Rome LC. 1984. Jumping performance of frog (Rana pipiens) as a function of muscle temperature. Journal of Experimental Biology 108: 429- 439.

Hsü CY, Yü NW, Liang HM. 1971. Induction of sex reversal in female tadpoles of Rana catesbeiana by temperature. Endocrinologia Japonica 18: 243-251 DOI 10.1507/endocrj1954.18.243.

Hu YC, Tang Y, Chen ZQ, Chen JY, Ding GH. 2019. Evaluation of the sensitivity of Microhyla fissipes tadpoles to aqueous cadmium. Ecotoxicology 28: 1150-1159 DOI 10.1007/s10646-019-02117-y.

Huey JE, Stevenson RD. 1979. Integrating thermal physiology and ecology of ectotherms: a discussion of approaches. American Zoologist 19: 357- 366 DOI 10.1093/icb/19.1.357.

Iwade R, Maruo K, Okada G, Nakamura M. 2008. Elevated expression of P450c17 (CYP17) during testicular formation in the frog. General and Comparative Endocrinology 155: 7987 DOI 10.1016/j.ygcen.2007.02.032.

Kato T, Matsui K, Takase M, Kobayashi M, Nakamura M. 2004. Expression of P450 aromatase protein in developing and in sex-reversed gonads of the $\mathrm{XX} / \mathrm{XY}$ type of the frog Rana rugosa. General and Comparative Endocrinology 137: 227-236 DOI 10.1016/j.ygcen.2004.03.013.

Kraak SBM, Pen I. 2002. Sex-determining mechanisms in vertebrates. // Hardy ICW, ed. Sex ratios: concepts and research methods. Cambridge: Cambridge University Press. 
448 Kuntz S, Chardard D, Chesnel A, Grillier-Vuissoz I, Flament S. 2003a. Steroids, aromatase 449 and sex differentiation of the newt Pleurodeles waltl. Cytogenetic and Genome Research $450 \quad$ 101: 283-288 DOI 10.1159/000074350.

451 Kuntz S, Chesnel A, Duterque-Coquillaud M, Grillier-Vuissoz I, Callier M, Dournon C, 452 Flament S, Chardard D. 2003b. Differential expression of P450 aromatase during gonadal 453 sex differentiation and sex reversal of the newt Pleurodeles waltl. Journal of Steroid Biochemistry and Molecular Biology 84: 89-100 DOI 10.1016/S0960-0760(03)00009-8.

Lamb HM, Adkins JC. 1998. Letrozole. Drugs 56: 1125-1140 DOI 10.2165/00003495199856060-00020.

Li H, Qu YF, Ding GH, Ji X. 2011. Life-history variation with respect to experienced thermal environments in the lizard, Eremias multiocellata (Lacertidae). Zoological Science 28: 332338 DOI 10.2108/zsj.28.332.

\section{Li HP, Ji JF, Hou KY, Jia TZ, Zhao HM, Xiao Y, Wang MP, Wang YF. 2007. Clinical} study of aromatase inhibitors in advanced breast cancer. Journal of peking university (health sciences) 39: 193-196 DOI: 10.3321/j.issn:1671-167X.2007.02.019.

Li S, You YL, Lin DJ. 2007. Gonad differentiation and the effects of temperature on sex determination in the rice frog Rana limnocharis. Acta Zoologica Sinica 54: 271-281.

Li XH, Zhao WG, Guo YM, Xue JH. 2001. Development of sexual gland and influence of temperature on sexual differentiation in Rana chensinensis. Zoological Research 22: 351356.

Li YY, Lin HR. 2000. Effects of dopamine, estradiol and testosterone on gonadotropin release from the pituitary fragments of Rana rugulosa. Zoological Research 21: 441-445.

Liu L, Li C, Li NB, Xu HF, Wang YZ. 2006. Effects of water temperature on tadpole phenotypic plasticity in Bufo gargarizans (Anura: Bufonidae). Sichuan Journal of Zoology 25: $214-217$.

Londos PL, Brook RJ. 1988. Effect of temperature acclimation on locomotory performance curves in the toad, Bufo woodhousii. Copeia 1988: 26-32 DOI: $10.2307 / 1445918$. 
475 Martyniuk CJ, Bissegger S, Langlois VS. 2013. Current perspectives on the androgen 5 alpha-

476 dihydrotestosterone (DHT) and 5 alpha-reductases in teleost fishes and amphibians.

477 General and Comparative Endocrinology 194: 264-274 DOI 10.1016/j.ygcen.2013.09.019.

478 Maruo K, Suda M, Yokoyama S, Oshima Y, Nakamura M. 2008. Steroidogenic gene

479 expression during sex determination in the frog Rana rugosa. General and Comparative

480 Endocrinology 158: 87-94 DOI 10.1016/j.ygcen.2008.04.019.

481 Mei YY, Zheng RQ, Zheng SJ, Yan H, Liu ZF, Zhang QP, Wang ZG, Hong Y. 2018. Gonad

482 differentiation and the effects of temperature on sex determination in Quasipaa spinosa.

483 Acta Ecologica Sinica 38: 4809-4816 DOI 10.5846 /stxb201706271159.

484 Meng SH. 2019. Morphology of the respiratory system in Ichthyopis bannonicus. Fuzhou, China:

485 Fujian Agriculture and Forestry University.

486 Miller K. 1982. Effect of temperature on sprint performance in the frog Xenopus laevis and the

487 salamander Necturus maculosus. Copeia 1982: 695-698.

488 Miyata S, Kubo T. 2000. In vitro effects of estradiol and aromatase inhibitor treatment on sex

489 differentiation in Xenopus laevis gonads. General and Comparative Endocrinology 119:

$490 \quad$ 105-110 DOI 10.1006/gcen.2000.7497.

491 Nakamura M. 2009. Sex determination in amphibians. Seminars in Cell \& Developmental

492 Biology 20: 271-282 DOI 10.1016/j.semcdb.2008.10.003.

493 Nakamura M. 2010. The mechanism of sex determination in vertebrates-are sex steroids the

494 key-factor? Journal of Experimental Zoology A 313: 381-398 DOI 10.1002/jez.616.

495 Nakamura M. 2013. Is a sex-determining gene(s) necessary for sex-determination in

496 amphibians? Steroid hormones may be the key factor. Sexual Development 7: 104-114 DOI

$497 \quad 10.1159 / 000339661$.

498 Nam YS, Lee G, Yun JM, Cho B. 2018. Testosterone replacement, muscle strength, and 499 physical function. World Journal of Men's Health 36: 110-122 DOI 10.5534/wjmh.182001.

500 Nathan L, Shi W, Dinh H, Mukherjee TK, Wang XP, Lusis AJ, Chaudhuri G. 2001.

501 Testosterone inhibits early atherogenesis by conversion to estradiol: Critical role of 
502

503

504

505

506

507

508

509

510

511

512

513

514

515

516

517

518

519

520

521

522

523

524

525

526

527

528

aromatase. Proceedings of the National Academy of Sciences of the United States of America 98: 3589-3593 DOI 10.1073/pnas.051003698.

Nie HY, Liu JK, Su JP, Zhang YM, Zhang HH. 2007. Progress in the study of animal life history evolution. Acta Ecologica Sinica 27: 4267-4277 DOI CNKI:SUN:STXB.0.2007-10039.

Nishioka M, Miura I, Saitoh K. 1993. Sex chromosomes of Rana rugosa with special reference to local differences in sex-determining mechanism. Scientific report of the Laboratory for Amphibian Biology. Scientific Report of the Laboratory for Amphibian Biology 12: 55-81 DOI $10.15027 / 14532$.

Noëlle RM, Mireille D, Gisèle D, Marc G, Claude P. 1995. Endocrine sex reversal of gonads by the aromatase inhibitor letrozole (CGS 20267) in Emys orbicularis, a turtle with temperature-dependent sex determination. General and Comparative Endocrinology 100: 314-326 DOI 10.1006/gcen.1995.1162.

Oike A, Kodama M, Nakamura Y, Nakamura M. 2016. A threshold dosage of testosterone for female-to-male sex reversal in Rana rugosa frogs. Journal of Experimental Zoology 325: 532-538 DOI 10.1002/jez.2037.

\section{Olmstead AW, Kosian PA, Korte JJ, Holcombe GW, Woodis KK, Degitz SJ. 2008. Sex} reversal of the amphibian, Xenopus tropicalis, following larval exposure to an aromatase inhibitor. Aquatic Toxicology 91: 143-150 DOI 10.1016/j.aquatox.2008.07.018.

Phuge SK. 2018. Effect of fromestane on gonadal sex differentiation and sex ratio in the frog, Euphlyctis cyanophlyctis, with undifferentiated type of gonadal differentiation. Journal of Herpetology 52: 171-175 DOI 10.1670/17-019.

Piprek RP, Pecio A, Kubiak JZ, Szymura JM. 2012. Differential effects of testosterone and 17ß-estradiol on gonadal development in five anuran species. Reproduction 144: 257-267 DOI 10.1530/REP-12-0048.

Piquet J. 1930. Déternination du sexe chez les batracuens enfonctin de la temperature. Revue Suisse De Zoologie 37: 173-281. 
529 Putnam RW, Bennett AF. 1981. Thermal dependence of behavioural performance of anuran 530 amphibians. Animal Behaviour 29: 502-509 DOI 10.1016/s0003-3472(81)80111-x.

531 Roff DA. 1990. Evolution of life histories. Science 248: 750-751 DOI 10.1016/0047-

$532 \quad 2484(91) 90077-9$.

533 Rome LC, Stevens ED, John-Alder HB. 1992. The influence of temperature and thermal 534 acclimation on physiological function. // Feder ME, Burggren WW, eds. Environmental

535 physiology of the amphibians. Chicago: University of Chicago Press.

536

Sandstrom O. 1995. Effects of temperature on life history variables in perch. Journal of Fish Biology 47: 652-670 DOI 10.1006/jfbi.1995.0169.

538

539

540

541

542

543

544

545

546

547

548

549

550

551

552

553

554

555

Shen ZG, Fan QX, Yang W, Zhang YL, Hu PP, Xie CX. 2013. Effects of non-steroidal aromatase inhibitor letrozole on sex inversion and spermatogenesis in yellow catfish Pelteobagrus fulvidraco. Biological Bulletin 225: 18-23 DOI 10.1086/BBLv225n1p18.

Singh AK, Srivastava PP, Verma R, Sharad CS, Dinesh K, Abubakar A. 2015. Effect of dietary administration of letrozole and tamoxifen on gonadal development, sex differentiation and biochemical changes in common carp (Cyprinus carpio L.). Reproduction, Fertility and Development 27: 449 DOI 10.1071/RD13234.

Stearns SC. 1992. The evolution of life histories. Oxford: Oxford University Press.

Stephanie T, Beata RK, Maria O, Andreas L, Petros L, Frauke H, Ilka L, Werner K, Matthias S. 2016. Sex reversal assessments reveal different vulnerability to endocrine disruption between deeply diverged anuran lineages. Scientific Reports 6: 23825 DOI $10.1038 /$ srep 23825 .

Tompsett AR, Wiseman S, Higley E, Giesy JP, Hecker M. 2013. Effects of exposure to $17 \alpha-$ ethynylestradiol during larval development on growth, sexual differentiation, and abundances of transcripts in the liver of the wood frog (Lithobates sylvaticus). Aquatic Toxicology 126: 42-51 DOI 10.1016/j.aquatox.2012.10.003.

Tracy CR. 1979. Further thoughts on anuran thermoregulation: discussion. // Burtt EH, ed. The behavioral significance of color. New York: Garland STPM Press.

Peer] reviewing PDF | (2019:07:39200:4:0:NEW 17 Feb 2020) 
556 Urbatzka R, Lutz I, Kloas W. 2007. Aromatase, steroid-5-alpha-reductase type 1 and type 2

557

558

559

560

561

562

563

564

565

566

567

568

569

570

571

572

573

574

575

576

577

578

579

580

581

mRNA expression in gonads and in brain of Xenopus laevis during ontogeny. General and Comparative Endocrinology 153: 280-288 DOI 10.1016/j.ygcen.2007.01.041.

Wang HP, Wang LZ. 2008. Research progress in thermal biology of Rana chensinensis. Sichuan Journal of Zoology 27: 478-480.

Wang LZ, Li XC. 2007. Effect of temperature on incubation and thermal tolerance of the Chinese forest frog. Chinese Journal of Zoology 42: 121-127.

Wang LZ, Li XC, Zhang CB. 2005. Temperature effect on development of tadpoles of Bufo gargarizans and Rana chensinensis. Sichuan Journal of Zoology 24: 355-358.

Whitehead PJ, Puckridge JT, Leigh CM, Seymour RS. 1989. Effect of temperature on jump performance of the frog Limnodynastes tasmaniensis. Physiological and Biochemical Zoology 62: 937-949 DOI 10.1086/physzool.62.4.30157938.

Wilson RS. 2001. Geographic variation in thermal sensitivity of jumping performance in the frog Limnodynastes peronii. Journal of Experimental Biology 204: 4227-4236.

Yoshikura M. 1959. The action of pituitary in sex differentiation and se reversal in amphibians. II. Effects of high temperature on the gonads of hypophysectomized frog larvae. Kumamoto Journal of Science B 4: 69-101.

Yu NW, Hsu CY, Ku HH, Chang LT, Liu HW. 1993. Gonadal differentiation and secretions of estradiol and testosterone of the ovaries of Rana catesbeiana tadpoles treated with 4hydroxyandrostenedione. Journal of Experimental Zoology 265: 252-257 DOI 10.1002/jez.1402650307.

Zhan JZ, Yang X. 2012. Efficient breeding technologies for economically important frogs. Beijing: Chemical Industry Press.

Zhang CY, Witschi E. 1956. Genic control and hormonal reversal of sex differentiation in Xenopus. Proceedings of The Society for Experimental Biology and Medicine 93: 140-141 DOI 10.3181/00379727-93-22688. 


\section{Table $\mathbf{1}$ (on next page)}

Table 1 Descriptive statistics, expressed as means \pm SE (range), for metamorphosis time, snout-vent length, body mass and condition factor of froglets, and results of twoway ANOVAs.

Tukey's post hoc comparison was performed on the trait that differed between the two temperature treatments. $\mathrm{T} 29: 29^{\circ} \mathrm{C}, \mathrm{T} 34: 34^{\circ} \mathrm{C}$. 
Table 1 Descriptive statistics, expressed as means \pm SE (range), for metamorphosis time, snout-vent length, body mass and condition factor of froglets, and results of two-way ANOVAs.

\begin{tabular}{|c|c|c|c|c|c|}
\hline $\begin{array}{l}\text { Temperature } \\
\left({ }^{\circ} \mathrm{C}\right)\end{array}$ & $\begin{array}{l}\text { Letrozole } \\
\text { concentration } \\
(\mathrm{mg} / \mathrm{g})\end{array}$ & $\begin{array}{l}\text { Metamorphosis time } \\
\text { (days) }\end{array}$ & $\begin{array}{l}\text { Snout-vent length } \\
(\mathrm{mm})\end{array}$ & $\begin{array}{l}\text { Body mass } \\
(\mathrm{g})\end{array}$ & $\begin{array}{l}\text { Condition factor } \\
(\mathrm{g} / \mathrm{mm})\end{array}$ \\
\hline \multirow{3}{*}{29} & 0 & $26.1 \pm 0.3(23-31)$ & $22.0 \pm 0.3(19.9-24.1)$ & $1.48 \pm 0.05(1.20-2.02)$ & $0.067 \pm 0.002(0.055-0.085)$ \\
\hline & 0.1 & $26.3 \pm 0.3(23-35)$ & $22.1 \pm 0.4(18.6-25.0)$ & $1.56 \pm 0.07(1.00-2.34)$ & $0.070 \pm 0.002(0.054-0.093)$ \\
\hline & 1 & $26.0 \pm 0.3(23-30)$ & $22.0 \pm 0.3(20.2-24.8)$ & $1.50 \pm 0.09(1.03-2.34)$ & $0.068 \pm 0.003(0.051-0.096)$ \\
\hline \multirow{3}{*}{34} & 0 & $20.8 \pm 0.3(17-25)$ & $21.2 \pm 0.2(19.6-23.2)$ & $1.36 \pm 0.03(1.11-1.69)$ & $0.064 \pm 0.002(0.051-0.082)$ \\
\hline & 0.1 & $21.0 \pm 0.2(17-28)$ & $21.5 \pm 0.3(19.1-24.7)$ & $1.32 \pm 0.03(1.09-1.67)$ & $0.062 \pm 0.001(0.051-0.076)$ \\
\hline & 1 & $21.3 \pm 0.3(17-28)$ & $21.3 \pm 0.3(18.6-23.1)$ & $1.39 \pm 0.04(1.11-1.72)$ & $0.065 \pm 0.002(0.052-0.081)$ \\
\hline \multirow{4}{*}{$\begin{array}{l}\text { Statistical } \\
\text { results }\end{array}$} & Temperature & $\begin{array}{l}\mathrm{F}_{1,326}=463.79 \\
\mathrm{P}<0.001 ; \mathrm{T} 29>\mathrm{T} 34\end{array}$ & $\begin{array}{l}\mathrm{F}_{1,114}=7.98 \\
\mathrm{P}<0.01 ; \mathrm{T} 29>\mathrm{T} 34\end{array}$ & $\begin{array}{l}\mathrm{F}_{1,114}=12.35 \\
\mathrm{P}<0.001 ; \mathrm{T} 29>\mathrm{T} 34\end{array}$ & $\begin{array}{l}\mathrm{F}_{1,114}=7.34 \\
\mathrm{P}<0.01 ; \mathrm{T} 29>\mathrm{T} 34\end{array}$ \\
\hline & Letrozole & $\mathrm{F}_{2,326}=0.29$ & $\mathrm{~F}_{2,114}=0.23$ & $\mathrm{~F}_{2,114}=0.11$ & $\mathrm{~F}_{2,114}=0.11$ \\
\hline & concentration & $\mathrm{P}=0.750$ & $\mathrm{P}=0.794$ & $\mathrm{P}=0.896$ & $\mathrm{P}=0.893$ \\
\hline & Interaction & $\begin{array}{l}\mathrm{F}_{2,326}=0.82 \\
\mathrm{P}=0.442\end{array}$ & $\begin{array}{l}F_{2,114}=0.03 \\
P=0.966\end{array}$ & $\begin{array}{l}F_{2,114}=0.91 \\
P=0.406\end{array}$ & $\begin{array}{l}\mathrm{F}_{2,114}=1.53 \\
\mathrm{P}=0.221\end{array}$ \\
\hline
\end{tabular}

3 Tukey's post hoc comparison was performed on the trait that differed between the two temperature treatments. T29: $29{ }^{\circ} \mathrm{C}, \mathrm{T} 34: 34$ $4{ }^{\circ} \mathrm{C}$. 
Figure 1

Figure 1 Metamorphosis rate of $H$. rugulosus tadpoles from treatments involving 2 temperatures $\times 3$ letrozole concentrations.

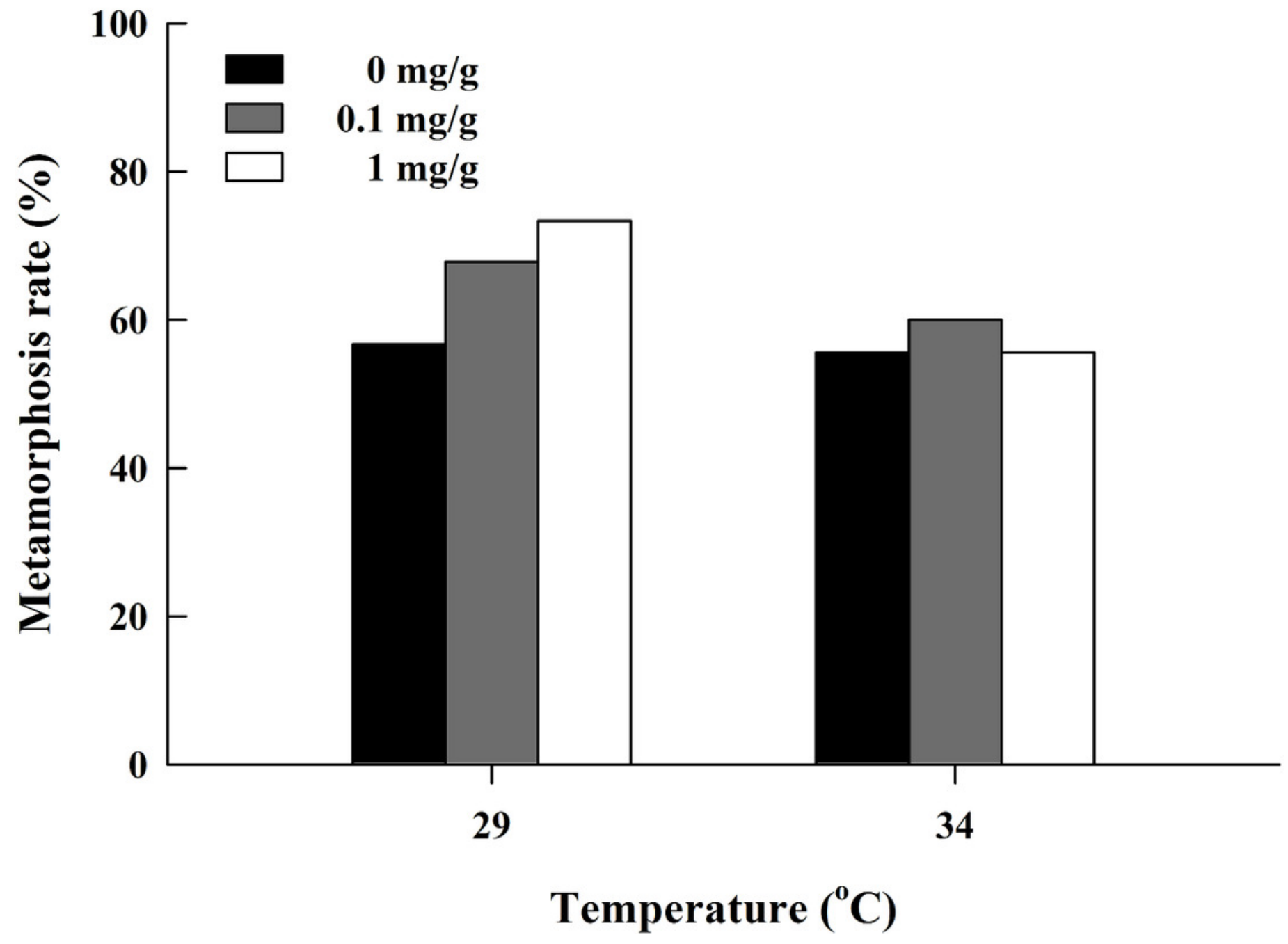


Figure 2

Figure 2 (A) Correlation of jumping distance with condition factor and (B) mean values (+SE) for residual of jumping distance of $H$. rugulosus froglets at complete metamorphosis from treatments involving 2 temperatures $\times 3$ letrozole concentrations.

Regression equation and coefficient are indicated in the figure. 

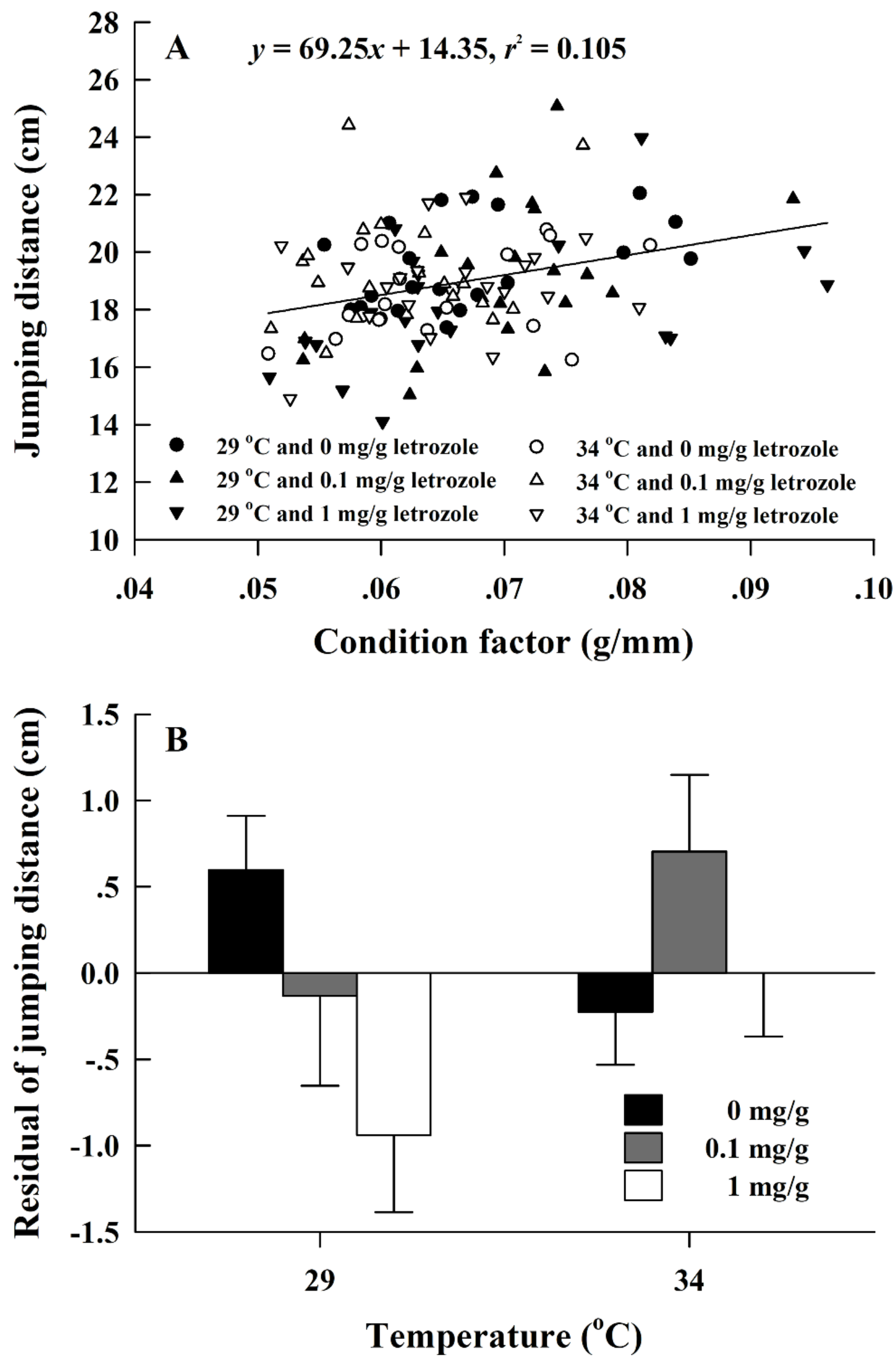
Figure 3

Figure 3 (A) Survival rate and (B) male ratio at 90 days after complete metamorphosis in $H$. rugulosus from treatments involving 2 temperatures $\times 3$ letrozole concentrations.

The sample sizes are indicated in the figure. 

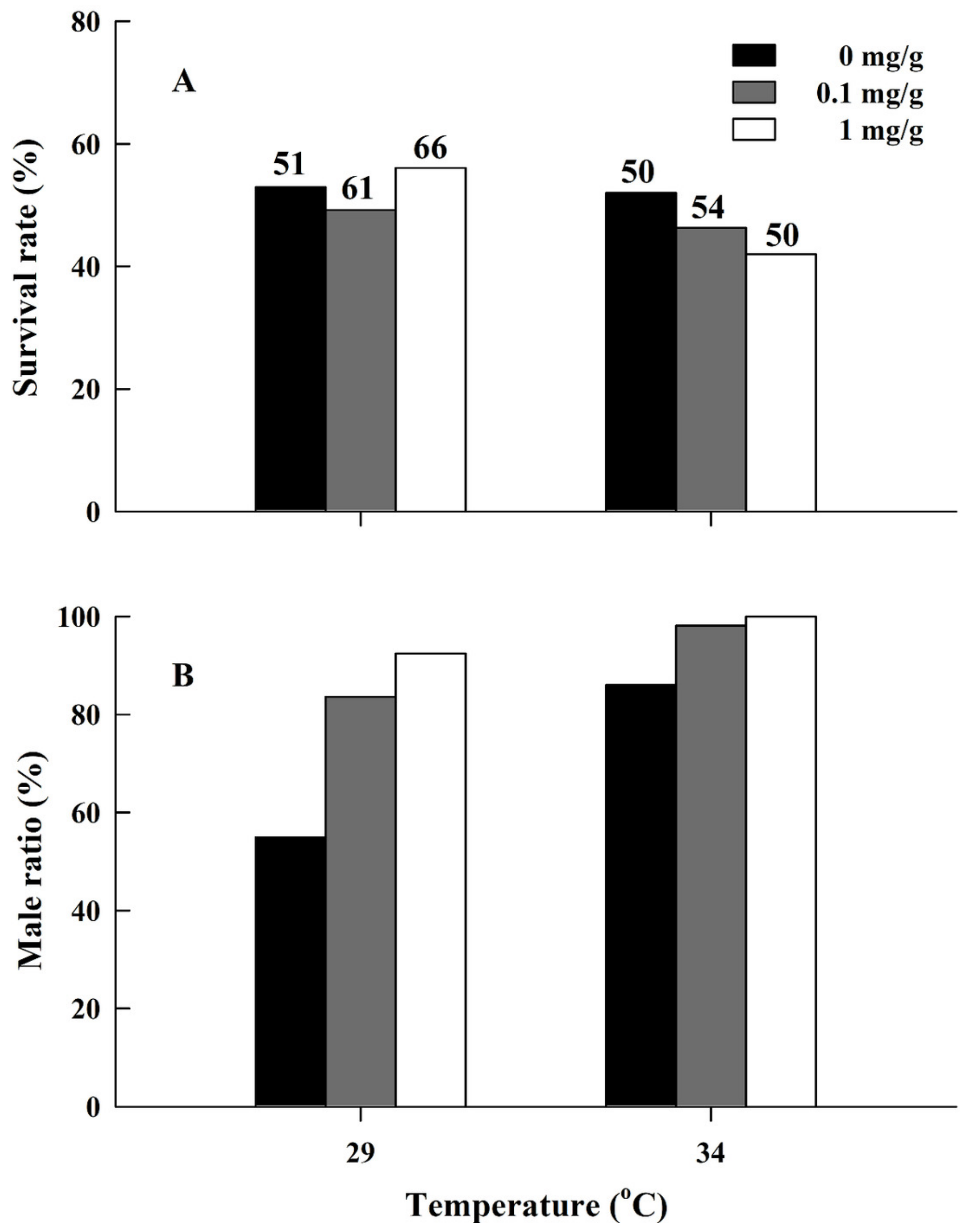